\title{
3D model related to the publication: A fossil terrestrial fauna from Tobène (Senegal) provides a unique early Pliocene window in western Africa
}

\author{
Fabrice Lihoreau ${ }^{1 *}$, Raphaël Sarr², Dominique Chardon ${ }^{3}$, Jean-Renaud Boisserie ${ }^{4,5}$, Renaud Lebrun ${ }^{1}$, Sylvain Adnet ${ }^{1}$, \\ Jérémy E. Martin ${ }^{6}$, Bernard Sambou², Rodolphe Tabuce ${ }^{1}$, Moustapha Thiam ${ }^{7}$, Lionel Hautier ${ }^{1}$ \\ ${ }^{1}$ Institut des Sciences de l'Evolution, UMR5554, CNRS, IRD, EPHE, Université de Montpellier, Montpellier, France \\ ${ }^{2}$ Département de Géologie, Faculté des Sciences et Techniques, Université Cheikh-Anta-Diop de Dakar, B. P. 5005 Dakar-Fann, Sénégal \\ ${ }^{3}$ GET, Université de Toulouse, IRD, CNRS, UPS, CNES, Toulouse F-31400, France \\ ${ }^{4}$ Palevoprim UMR 7262, CNRS, Université de Poitiers, France \\ ${ }^{5}$ Centre Français des Études Éthiopiennes, USR 3137, CNRS, Ministère de l'Europe et des19 affaires étrangères, Addis Abeba, Éthiopie \\ ${ }^{6}$ Univ. Lyon, ENS de Lyon, Université Claude Bernard Lyon 1, CNRS, UMR 5276 Laboratoire de Géologie de Lyon: Terre, Planètes, Environnement, \\ F-69342 46 Allée d'Italie, Lyon, France \\ ${ }^{7}$ Laboratoire de Biostratigraphie et Sédimentologie, Département de Géologie, Faculté des Sciences et Techniques, Université Cheikh-Anta-Diop de \\ Dakar, B. P. 5005 Dakar-Fann, Sénégal. \\ ${ }^{*}$ Corresponding author: fabrice.lihoreau@umontpellier.fr
}

\begin{abstract}
The present contribution contains the 3D virtual restoration of a Pliocene right femur belonging to a Lutrinae indet. (Carnivora) from Tobène, Senegal, described and figured in Lihoreau et al. (2021) : "A fossil terrestrial fauna from Tobène (Senegal) provides a unique early Pliocene window in Western Africa ". https://doi.org/10.1016/j.gr.2021.06.013
\end{abstract}

Keywords: Carnivora, Lutrinae, Femur, Pliocene, Senegal

Submitted:2020-06-03, published online:2021-06-24. https://doi.org/10.18563/journal.m3.102

Inv nr.

Description

SN-Tob-12-02 3D surface virtual restoration

Table 1. Related model of a right femur belonging to a Carnivora (Lutrinae indet). Collection: Université Cheikh-Anta-Diop, Dakar, Senegal.

\section{INTRODUCTION}

SN-Tob-12-02 is an uncomplete right femur of Lutrinae indet, preserving a fragmentary portion of the proximal part of the diaphysis, as well as a fragmentary distal extremity, including the condyles. This specimen belongs to the fauna retrieved from the Pliocene locality of Tobène, Senegal. As most specimens from this locality, SN-Tob-12-02 is fragmentary, and several parts, such as the patellar facet have been shifted post-mortem. Therefore, a virtual restoration of this specimen was performed and is presented here (see Table 1 and Fig. 1).

\section{METHODS}

SN-Tob-12-02 was digitized using X-ray microtomography $(\mu \mathrm{CT})$ using an EasyTom 150 microtomograph (MRI platform). The distal extremity of this femur contains four main fragments (the patellar facet, a part of the lateral condyle, the medial condyle, and a part of proximal shaft), which had been slightly broken and displaced post-mortem. 3D surfaces representing these four parts were extracted with Avizo 9.2 (Thermo Fisher Scientific). The surfaces belonging to the distal extremity and to the proximal part of the diaphysis were positioned in space with MorphoDig software (Lebrun, 2018) in order to retrieve anatomical connection.

\section{ACKNOWLEDGEMENTS}

3D data acquisitions were performed using the $\mu \mathrm{CT}$ facilities of the MRI platform member of the national infrastructure FranceBioImaging supported by the French National Research Agency (ANR-10-INBS-04, «Investments for the future $\gg$ ), and of the Labex CEMEB (ANR-10-LABX-0004) and NUMEV (ANR10-LABX-0020).

\section{BIBLIOGRAPHY}

Fabrice Lihoreau, Raphä̈l Sarr, Dominique Chardon, JeanRenaud Boisserie, Renaud Lebrun, Sylvain Adnet, Jeremy Martin, Bernard Sambou, Rodolphe Tabuce, Mohamadou M. Thiam, Lionel Hautier (2021). A fossil terrestrial fauna from Tobène (Senegal) provides a unique early Pliocene window in western Africa. Gondwana Research. https://doi.org/10.1016/j. gr.2021.06.013 


\section{A}

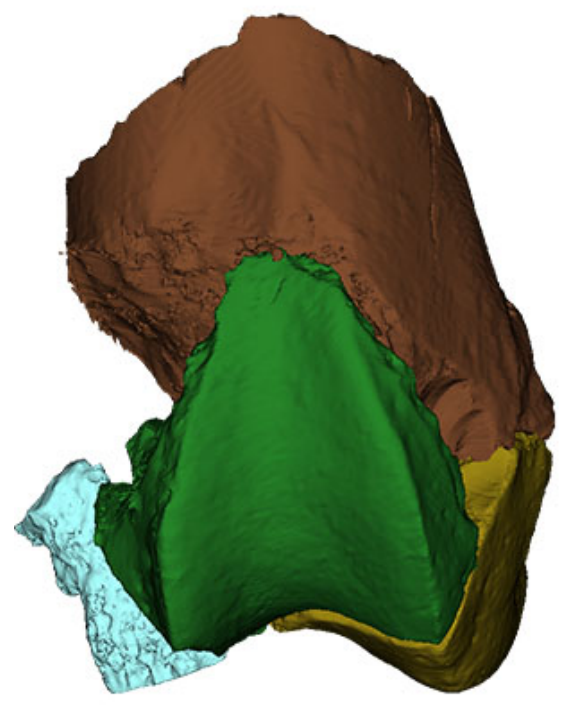

B

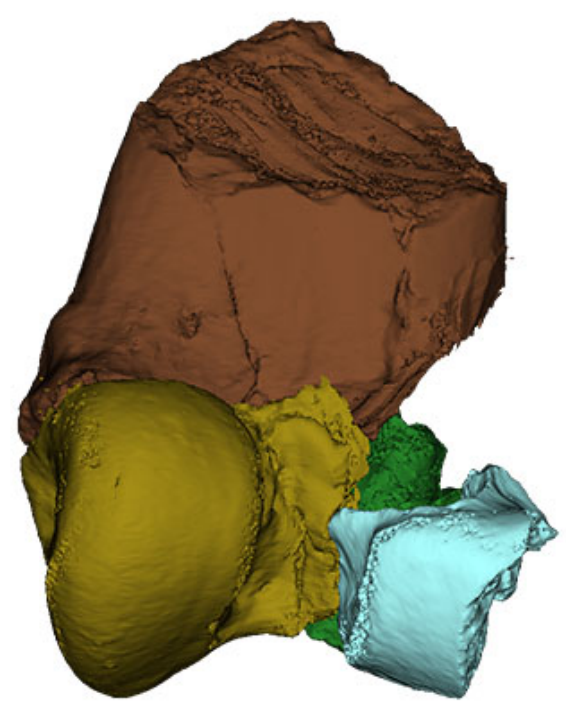

$1 \mathrm{~cm}$
C

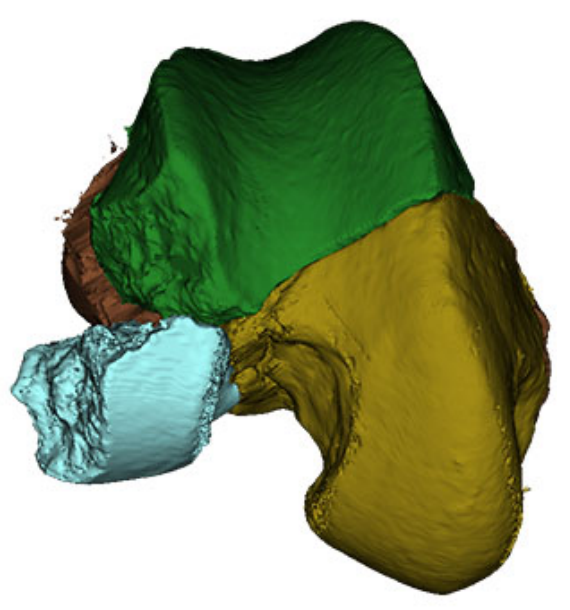

Figure 1. Distal extremity of SN-Tob-12-02 in cranial (A) caudal (B) and distal (C) orientation. Brown: proximal shaft fragment. Green: patellar facet. Yellow: medial condyle. Cyan: lateral condyle fragment. 